\title{
The effects of enriching white bread with vegetables on measures of hunger in young women
}

\author{
T. W. George, V. Sharma, L. Methven and J. A. Lovegrove \\ Department of Food Biosciences, The University of Reading, Whiteknights, Reading RG6 6AP, Berks., UK
}

Current recommendations suggest that a daily intake of $400 \mathrm{~g}$ fruit and vegetables is required for the prevention of chronic diseases ${ }^{(1)}$. The UK Government recommends that this intake consists of five $80 \mathrm{~g}$ portions per $\mathrm{d}^{(2)}$. However, the average UK adult only consumes 2.8 portions per $\mathrm{d}^{(3)}$. Thus, new strategies to increase fruit and vegetable consumption are required. The incorporation of whole fruits and vegetables into the matrix of foods, such as bread, provides a novel approach to increasing their consumption. In addition, fruits and vegetables may help to combat obesity by limiting the consumption of more energy-dense foods ${ }^{(4,5)}$. A study investigating the satiating effects of incorporating whole vegetables into sliced bread was performed. The study was given approval after ethical review. Subjects gave informed consent.

Seventeen females, aged 18-35 years, participated in a randomised controlled within-subject cross-over design study investigating the effects of enriching white bread with carrots or tomatoes (40\% vegetable matter; w/w) on postprandial satiety. The subjects consumed a standard breakfast of frosted cereal flakes $(50 \mathrm{~g})$ and semi-skimmed milk $(250 \mathrm{~g})$ and test lunches on three occasions, $\geq 1$ week apart. The test lunches comprised of sandwiches made from two slices of bread $(100 \mathrm{~g})$ with a filling of full-fat cream cheese (40 g) and cucumber $(20 \mathrm{~g})$ using three types of bread: white; carrot-containing; tomato-containing. The fresh vegetable material was either homogenised (33\%; $\mathrm{w} / \mathrm{w})$ or diced $(7 \% ; \mathrm{w} / \mathrm{w})$ before incorporation into the dough. The slices of bread were of equal mass across treatments. The subjects completed visual analogue scales using Compusense computer software (Compusense Inc., Guelph, ON, Canada) to assess post-lunch satiety, hunger motivation, mood and mental alertness at $30 \mathrm{~min}$ intervals for a $4 \mathrm{~h}$ period after consumption of the test lunch.

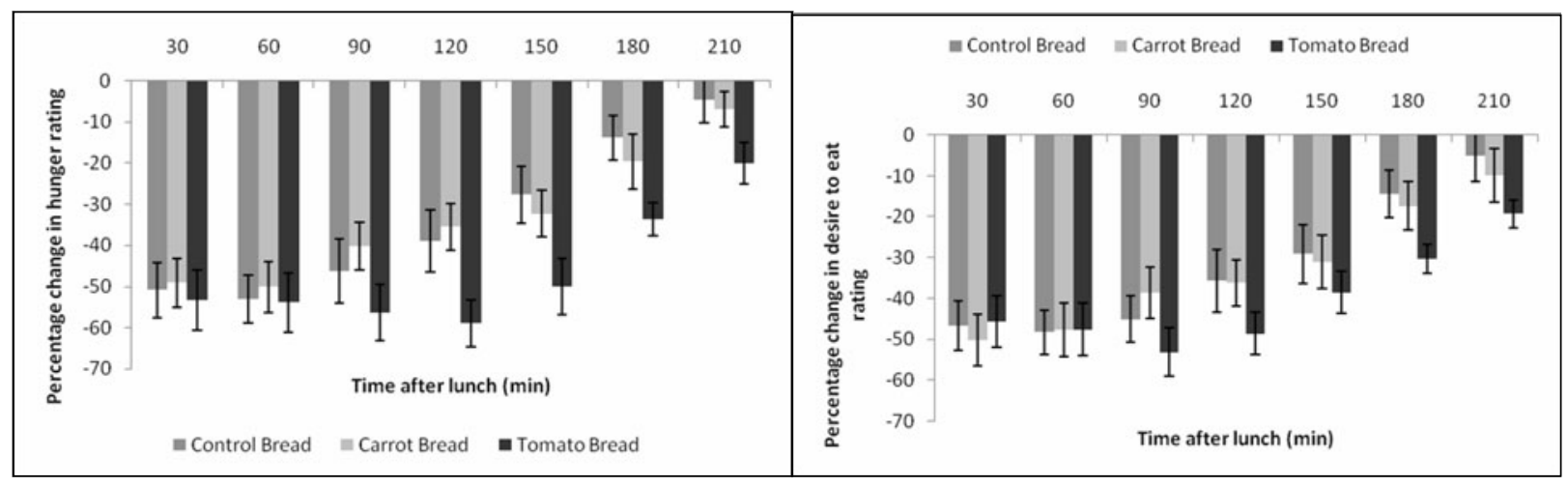

It was observed that the tomato-enriched bread significantly decreased the rating of hunger over the $4 \mathrm{~h}$ postprandial period compared with the control and carrot-enriched bread $(P=0.022$ and $P=0.001$ respectively). The tomato-enriched bread also significantly decreased the desire to eat in the subjects compared with the control bread $(P=0.020)$.

Overall, the current study provides evidence that enriching white bread with vegetables can reduce hunger. Further studies are required to determine the benefit of chronic consumption of these products in relation to satiety and hunger.

1. World Health Organization (2003) Diet, Nutrition and the Prevention of Chronic Diseases. Report of a Joint WHO/FAO Expert Consultation. Geneva: WHO.

2. Food Standards Agency (2009) Eat well, be well: healthy diet - fruit and veg. http://www.eatwell.gov.uk/healthydiet/nutritionessentials/fruitandveg/

3. Hoare J, Henderson L, Bates CJ et al. (2004) The National Diet and Nutrition Survey: Adults Aged 19 to 64 Years. London: The Stationery Office.

4. Astrup A, Neilsen CM \& Jebb SA (2004) Obes Rev 5, 89-90.

5. Rolls BJ, Ello-Martin JA \& Tohill BC (2004) Nutr Rev 62, 1-17. 